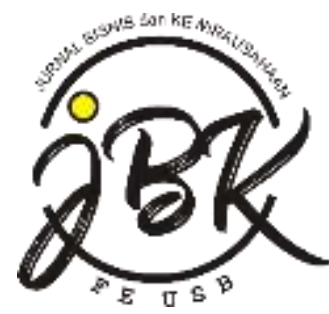

\title{
PENGARUH PERSEPSI POLITIK ORGANISASIONAL TERHADAP KEPUASAN KERJA YANG DIMODERASI KETRAMPILAN POLITIK
}

\author{
Fauziah Jahra Cintana ${ }^{1}$ \\ Universitas Setia Budi Surakarta \\ (jahracintaa@gmail.com) \\ Nang Among Budiadi² \\ Universitas Setia Budi Surakarta \\ (nangamongbudiadi@gmail.com) \\ Sugiyarmasto ${ }^{3}$ \\ Universitas Setia Budi Surakarta \\ (syarmasto@yahoo.com)
}

\begin{abstract}
The purpose of this study is to examine the effect of organizational political perceptions on job satisfaction moderated by political skills. This research is important because it is able to examine the significance of the relationship between organizational political perceptions and political skills on job satisfaction. This research uses survey research methods through questionnaires. The object of research is all hospital employees in the city of Surakarta with a sample of 159 respondents. Sampling in this study using the probability sampling method. The analytical tool used in this study is simple linear regression while the moderating analysis tool uses regression analysis tools. The results showed $\mathrm{H} 1$ had a significant relationship while $\mathrm{H} 2$ did not have a significant relationship. These results give the sense that organizational political perceptions affect job satisfaction. While political skills as a moderator between organizational political perceptions do not affect job satisfaction.
\end{abstract}

Keywords: job satisfaction, organizational political perceptions and political skills.

\section{A. PENDAHULUAN}

Karyawan merupakan salah satu
unsur untuk menentukan maju dan mundurnya organisasi. Dalam upaya mencapai tujuannya, maka organisasi perlu memberikan kepuasan kerja pada karyawannya agar dapat menghasilkan kinerja baik. Kepuasan kerja ini ditentukan oleh perasaan karyawan terhadap pekerjaannya (Spector, 1997).

Kepuasan kerja digambarkan sebagai perilaku terhadap suatu pekerjaan yang dihasilkan dari penilaian prestasi kerja, kondisi kantor, dan kehidupan profesional seseorang (Golbasi et al., 2008). Dawis dan Lofquist (1984) menyatakan kepuasan kerja merupakan kondisi afektif menyenangkan yang dihasilkan dari penilaian seseorang tentang cara dimana situasi pekerjaan yang dialami memenuhi kebutuhan, nilai, dan harapan seseorang.

Penelitian konseptual kepuasan kerja mengungkapkan dua komponen utama dalam definisi dan pengukuran konsep yaitu afektif dan kognitif. Locke (1976 h. 1300), menyatakan bahwa kepuasan kerja berasal 
dari perspektif afektif. Menurut pernyataannya, kepuasan kerja dapat didefinisikan sebagai keadaan emosional yang menyenangkan atau positif yang dihasilkan dari penilaian pekerjaan atau pengalaman kerja seseorang. Perspektif kepuasan kerja secara substansial terkait dengan emosi seseorang, oleh karena itu penilaian individu di mana pekerjaan memenuhi nilai-nilai kinerja seseorang dapat menyebabkan kepuasan emosional yang positif atau ketidakpuasan (Coomber dan Barriball, 2007 hal. 297). Komponen kognitif kepuasan kerja didefinisikan dalam hal perbedaan antara persepsi individu tentang situasi dan standar yang diketahui tingkat harapannya (Campbell et al., 1976).

Menurut Belfield dan Harris (2002); Vieira (2005), semakin tinggi tingkat kepuasan kerja, semakin baik pekerjaan itu cocok dengan keterampilan mereka. Bukti meta analitik (Chang et al., 2009; Miller et al., 2008) telah menunjukkan bahwa perusahaan-perusahaan dengan politik disfungsional berhubungan negatif dengan sikap karyawan dan perilaku. Miller dan rekan-rekannya menunjukkan bahwa persepsi politik berkorelasi positif dengan stres kerja dan niat berpindah dan berkolerasi negatif dengan kepuasan kerja.

Penelitian ini lebih berfokus pada variabel-variabel yang terkait dengan persepsi politik organisasional dalam memengaruhi kepuasan kerja. Berbagai penelitian mengenai kepuasan kerja masing- masing membuat pemodelan yang melibatkan variabel-variabel independen yang berbeda. Sejumlah penelitian melaporkan adanya hubungan negatif antara persepsi politik organisasional dan kepuasan kerja (Drory, 1993). Penelitian Meisler dan Vigoda-Gadot (2014) menemukan ada hubungan negatif antara politik terhadap sikap dan kinerja pekerjaan. Vigoda dan Tahmud, (2010) dalam penelitiannya menemukan hubungan negatif antara persepsi politik organisasional dan kepuasan kerja. Studi Miller et al., (2008) dalam investigasi ekstensif telah menemukan hubungan negatif yang kuat antara persepsi politik organisasional dan kepuasan kerja. Penelitian lebih lanjut yang dilakukan Brouer et al., (2011) menyatakan bahwa ketrampilan politik tidak memoderasi hubungan negatif antara persepsi politik organisasional dan kepuasan kerja.

Masalah politik yang terkait dengan pekerjaan merupakan fenomena yang umum terjadi disetiap organisasi. Namun demikian, penelitian terdahulu banyak dilakukan di organisasi yang bukan rumah sakit. Untuk itu, hubungan ini perlu dibuktikan dalam konteks organisasi rumah sakit.

\section{B. TELAAH LITERATUR}

\section{Kepuasan Kerja}

Kepuasan kerja didefinisikan sebagai reaksi afektif terhadap pekerjaan yang dihasilkan dari perbandingan hasil yang dirasakan dengan yang diinginkan (Fung- 
Kam, 1998; Larson et al., 1984; Tovey dan Adams, 1999). Menurut Adams dan Bond (2000), definisi kepuasan adalah tingkat pendekatan positif terkait dengan pekerjaan atau dengan elemen-elemen pekerjaan. Berdasarkan sejumlah pengertian di atas, maka kepuasan kerja dapat didefinisikan sebagai reaksi afektif yang dihasilkan dari perbandingan antara harapan dan hasil yang diinginkan (Larson et al., 1984; Fung-Kam, 1998; Tovey dan Adams, 1999; Adams dan Bond, 2000).

Studi dari Saxena et al. (2005) dalam penelitiannya menggunakan indikator pengukuran kepuasan kerja: akrab dengan orang ditempat kerja, senang bekerja, pengakuan atas pekerjaan yang baik, aman dengan pekerjaan, pekerjaan yang dilakukan baik. Studi terdahulu menyatakan bahwa perusahaan-perusahaan dengan konflik politik berhubungan negatif dengan sikap karyawan dan perilaku (Chang et al., 2009; Miller et al., 2008). Miller dan rekan-rekan nya menunjukkan bahwa persepsi politik berkorelasi negatif dengan kepuasan kerja. Ferris et al. (1989) menemukan bahwa karyawan dengan persepsi politik organisasional yang tinggi tidak puas dengan pekerjaan mereka dan sebaliknya persepsi politik organisasional yang lebih rendah membawa kepuasan kerja yang lebih tinggi.

\section{Persepsi Politik Organisasional}

Politik organisasional didefinisikan sebagai pemahaman terhadap perilaku orang lain yang dirancang secara strategis untuk memaksimalkan kepentingan diri sendiri (Ferris et al., 1989) dan karenanya bertentangan dengan tujuan organisasi atau kepentingan individu lain. Persepsi politik organisasional menjelaskan penilaian terhadap perilaku dan sikap karyawan yang diarahkan menuju pencapaian tujuan tertentu. Persepsi politik organisasional dianggap karyawan sebagai pemahaman terhadap perilaku mementingkan diri sendiri dengan mengorbankan orang lain dan terkadang bertentangan dengan kepentingan manajemen organisasi. Studi dari Drory (1993); Ferris dan Kacmar, (1992) menemukan bahwa persepsi politik organisasional dianggap sebagai penilaian terhadap perilaku mementingkan diri sendiri oleh karyawan untuk mencapai kepentingan pribadi, keuntungan, mengorbankan orang lain dan terkadang bertentangan dengan kepentingan organisasi atau unit kerja. Perilaku ini sering dikaitkan dengan manipulasi, pencemaran nama baik, subversif, dan cara-cara ilegal menggunakan kekuasaan secara berlebihan untuk mencapai tujuan seseorang. Karyawan cenderung menggunakan beberapa taktik pengaruh untuk mencapai tujuan yang tidak ditentukan oleh organisasi atau untuk mencapai tujuan tertentu yang ditentukan oleh organisasi.

Studi dari Ferris et al. (1989), Kacmar et al. (1999) dan Sigri dan Basar (2015) menyatakan jika karyawan tidak bisa 
menghadapi atau mengelola politik ditempat kerjanya, maka mereka akan mempersepsikan politik organisasional sebagai ancaman bagi kesejahteraan, ketenangan, dan martabat mereka dan berakibat timbulnya hasil negatif. Akibat negatif itu dapat menimbulkan ketidakpuasan kerja. Medison et al. (1980) mengamati bahwa ketika individu diminta untuk menggambarkan politik di tempat kerja, mereka biasanya melakukan kegiatan mementingkan diri sendiri dan manipulatif yang tidak dirasakan secara positif. Ferris et al. (1989) menyatakan ada tiga bentuk respons potensial: peningkatan kecemasan kerja, penurunan kepuasan kerja, dan penarikan dari organisasi.

Chen dan Fang (2008) dalam penelitiannya mengajukan indikator pengukuran persepsi politik organisasional: praktek dan kebijakan organisasi, perilaku rekan kerja dan mencapai suatu tujuan. Studi terdahulu menyatakan bahwa persepsi tentang politik berhubungan negatif dengan kepuasan kerja (Drory, 1993). Studi lain Ferris et al. (1996b, 1998) menemukan bahwa persepsi politik organisasional berhubungan negatif dengan kepuasan kerja. Namun, penelitian yang dilakukan Parker et al. (1995) menemukan bahwa politik organisasional tidak terkait dengan kepuasan kerja. Atas dasar uraian diatas, maka dapat diajukan hipotesis sebagai berikut :

\section{H1: Persepsi politik organisasional berhubungan negatif dengan kepuasan kerja.}

\section{Ketrampilan Politik}

Keterampilan politik didefinisikan sebagai kemampuan secara efektif memahami orang lain di tempat kerja, dan menggunakan pengetahuan tersebut untuk mempengaruhi orang lain untuk bertindak dengan cara meningkatkan tujuan pribadi atau organisasi seseorang (Ferris, Treadway et al. (2005), hal 127. Mintzberg (1983) mendefinisikan keterampilan politik sebagai kemampuan secara efektif memahami orang lain di tempat kerja, dan menggunakan pengetahuan tersebut untuk memengaruhi orang lain untuk bertindak dengan cara meningkatkan tujuan pribadi atau organisasi seseorang. Ferris et al. (2007) mendefinisikan keterampilan politik adalah tentang kompetensi yang dimanifestasikan dalam situasi yang relevan dengan pekerjaan yang mencerminkan anteseden disposisi dan variabilitas situasional. Ahearn et al. (2004); Ferris et al. (2005b) mendefinisikan ketrampilan politik sebagai kemampuan untuk memahami secara efektif orang lain di tempat kerja, dan menggunakan pengetahuan memengaruhi orang lain untuk bertindak dengan cara meningkatkan tujuan pribadi atau organisasi.

Mintzberg (1983) menganggap ketrampilan politik diperlukan untuk keterlibatan pribadi yang efektif dalam organisasi. Penelitian terbaru telah 
Jurnal Bisnis dan Kewirausahaan

menekankan aspek kognitif dan interpersonal dari keterampilan politik. Zellars et al. (2008) menggambarkannya sebagai konstruk gaya interpersonal yang menggabungkan sosial kecerdikan dengan kapasitas untuk menyesuaikan perilaku sendiri terhadap tuntutan situasional yang berbeda dalam sikap yang tampaknya tulus, menginspirasi kepercayaan, dan menghasilkan pengaruh yang efektif terhadap orang lain. Ferris et al. (2007) menganggap ketrampilan politik sebagai pola kompetensi sosial yang komprehensif, yang mencerminkan manifestasi kognitif, afektif dan perilaku, dan memperagakan efek pada diri sendiri dan orang lain. Hal ini ditandai dengan persepsi sosial dan kemampuan menyesuaikan perilaku seseorang untuk berbeda dan merubah kebutuhan situasional (Ferris et al., 1999, 2005). Individu yang memiliki ketrampilan politik memiliki gaya interpersonal yang khas itu memberi mereka rasa percaya diri dan pengaruh interpersonal yang lebih besar (Ferris et al., 1999).

\section{Vol-13/No-2/Oktober/2020}

Ferris et al. (2005b),

(2007)

mengajukan indikator pengukuran ketrampilan politik yaitu kecerdasan sosial; pengaruh interpersonal; kemampuan berjaring; dan ketulusan. Gallagher dan Laird (2008) menemukan bahwa ketrampilan politik melemahkan pengaruh persepsi politik organisasional dan kepuasan kerja. Brouer et al. (2011) mengasumsikan bahwa ketika persepsi politik organisasi tinggi, individu mungkin tidak yakin bahwa kerja keras akan menghasilkan hasil yang diinginkan, bahwa kinerja yang baik akan diakui atau hadiah akan diinginkan. Namun, Brouer et al. (2011) menunjukkan ketrampilan politik itu tidak memoderasi hubungan antara persepsi politik organisasi dan hasil yang terkait dengan pekerjaan (kepuasan kerja, kinerja, dan komitmen yang dinilai manajer). Atas dasar uraian diatas, maka dapat diajukan hipotesis sebagai berikut :

H2 : Ketrampilan politik memoderasi hubungan negatif antara persepsi politik organisasi dan kepuasan kerja.

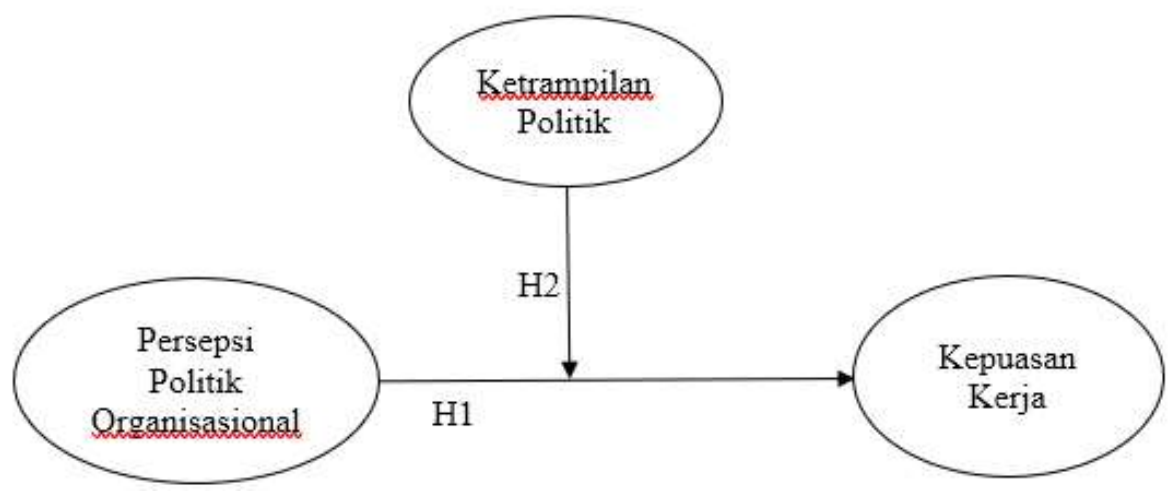

Gambar 1. Model Penelitian 


\section{METODE PENELITIAN}

Penelitian ini adalah penelitian kausal yang bertujuan menguji hubungan sebab akibat antar variabel yang diteliti. Penelitian ini bersifat cross sectional dan desain penelitian ini menggunakan metode survei. Obyek dalam penelitian ini adalah karyawan di Rumah Sakit Jiwa Daerah Surakarta dan karyawan di RS PKU Muhammadiyah Surakarta yang total jumlah seluruhnya adalah 159 karyawan. Teknik penyampelan yang digunakan adalah probability sampling dan cluster sampling. Pengujian alat ukur dalam penelitian ini menggunakan uji validitas dan uji reliabilitas dengan program SPSS. Uji hipotesis dalam penelitian ini dilakukan dengan analisis regresi moderasi.

\section{HASIL DAN PEMBAHASAN}

Hasil pengujian pada 6 item kuesioner adalah valid yang loading factor nya lebih dari 0,4 serta tidak mempunyai nilai ganda. Beberapa butir kuesioner harus dihilangkan karena tidak berkorelasi (bergerombol) dengan butir kuesioner lainnya dalam satu faktor yaitu KK2, KK3, KK4, PPO1,KP1, KP4 yang mengindikasikan tidak valid. Pengujian reliabilitas menunjukkan bahwa semua item kuesioner dalam variabel yang diteliti mempunyai nilai reliabilitas lebih dari 0,6 sehingga dapat disimpulkan semua item kuesioner reliabel digunakan dalam mengambil data.

\begin{tabular}{cccc}
\hline $\begin{array}{c}\text { Butir } \\
\text { Kuesioner }\end{array}$ & $\begin{array}{c}\text { Loading factor } \\
\text { Minimal }=0,40\end{array}$ & $\begin{array}{c}\text { Koefisien Alpha } \\
\text { (Nilai minimum }=0,6)\end{array}$ & Keterangan \\
\hline KK1 & 0,859 & 0,653 & Valid dan Reliabel \\
KK5 & 0,784 & & Valid dan Reliabel \\
PPO2 & 0,864 & 0,660 & Valid dan Reliabel \\
PPO3 & 0,821 & 0,709 & \\
KP2 & 0,811 & 0,887 & \\
KP3 & 0 &
\end{tabular}

Tabel 1. Hasil Uji Validitas Kuesioner

\begin{tabular}{|c|c|c|c|c|c|c|c|}
\hline \multirow{2}{*}{ Variabel } & \multirow{2}{*}{$\begin{array}{c}\text { Koefisien } \\
\text { Determinasi } \\
\begin{array}{c}\text { Adjusted R } \\
\text { Square }\end{array}\end{array}$} & \multicolumn{2}{|c|}{$\begin{array}{l}\text { Uji Signifikansi } \\
\text { Model }\end{array}$} & \multicolumn{2}{|c|}{$\begin{array}{c}\text { Uji Signifikansi } \\
\text { Koefisiensi Regresi }\end{array}$} & \multirow[t]{2}{*}{ Hasil } & \multirow{2}{*}{$\begin{array}{c}\text { Ket. } \\
\text { Pengujiian }\end{array}$} \\
\hline & & $\mathrm{F}$ & Sig. & Beta & Sig. & & \\
\hline \multicolumn{8}{|l|}{ Regresi 1} \\
\hline $\begin{array}{l}\mathrm{PPO} \longrightarrow \mathrm{KK} \\
\text { Regresi } 2\end{array}$ & 0,153 & 28,259 & 0,000 & 0,391 & 0,000 & Sig & Terdukung \\
\hline $\begin{array}{l}\text { KP\&PPO } \longrightarrow \mathrm{KK} \\
\text { Regresi } 3 \text { } \\
\text { PPO\&KP } \longrightarrow \text { KK }\end{array}$ & 0,257 & 28,359 & 0,000 & 0,306 & 0,000 & $\begin{array}{l}\text { Sig } \\
\text { Sig }\end{array}$ & Terdukung \\
\hline PPO & 0,147 & 28,259 & 0,000 & 0,930 & 0,000 & Sig & Terdukung \\
\hline $\mathrm{KP}$ & 0,257 & 28,359 & 0,000 & 1,082 & 0,000 & Sig & Terdukung \\
\hline Interaksi & 0,310 & 24,680 & 0,000 & $-1,098$ & 0,000 & Sig & Terdukung \\
\hline
\end{tabular}

Sumber : Data primer yang telah diolah (2020)

Tabel 2. Hasil Analisis Regresi 
Jurnal Bisnis dan Kewirausahaan

Berdasarkan hasil pengolahan data diketahui bahwa $\mathrm{H} 1$ terdukung dimana nilai beta 0,391 dan nilai $p$ kurang dari 0,05. Sedangkan $\mathrm{H} 2$ tidak terdukung karna memiliki beta $-1,098$ dengan $p$ kurang dari 0,05 .

\section{E. PEMBAHASAN}

Politik organisasional didefinisikan sebagai pemahaman terhadap perilaku orang lain yang dirancang secara strategis untuk memaksimalkan kepentingan diri sendiri (Ferris et al., 1989) dan karenanya bertentangan dengan tujuan organisasi atau kepentingan individu lain. Sedangkan kepuasan kerja didefinisikan sebagai reaksi afektif terhadap pekerjaan yang dihasilkan dari perbandingan hasil yang dirasakan dengan yang diinginkan (Fung-Kam, 1998; Larson et al., 1984; Tovey dan Adams, 1999).

Berdasarkan hasil analisis data dalam penelitian ini secara statistik membuktikan bahwa persepsi politik organisasional berpengaruh negatif terhadap kepuasan kerja. Hasil penelitian ini didukung oleh penelitian Ferris et al., (1989) bahwa karyawan dengan persepsi politik organisasional yang tinggi tidak puas dengan pekerjaannya dan persepsi politik organisasional yang rendah akan membawa kepuasan kerja yang tinggi bagi karyawan. Hasil studi yang sama dilakukan Rawwas et al., (2018) yang menyatakan bahwa persepsi politik organisasional berhubungan negatif terhadap kepuasan kerja. Hubungan negatif ini menunjukkan bahwa dilingkungan persepsi
Vol-13/No-2/Oktober/2020

politik organisasional, karyawan akan melihat perlakuan yang tidak sama yang akan menciptakan rasa ketidakpuasan terhadap suatu pekerjaan. Berdasarkan hasil penelitian terdahulu dan hasil penelitian yang telah dilakukan dapat dimaknai bahwa persepsi politik organisasional berhubungan negatif terhadap kepuasan kerja karyawan.

Berdasarkan hasil uji hipotesis menggunakan analisis regresi menunjukan bahwa ketrampilan politik melemahkan hubungan antara persepsi politik organisasional terhadap kepuasan kerja. Hasil menunjukan koefisien determinasi 0.310 . Hal ini menjelaskan bahwa persepsi politik organisasional dan kepuasan kerja menjelaskan 31 persen variasi pada ketrampilan politik. Maka dapat disimpulkan ketrampilan politik dan persepsi politik organisasional tidak memprediksi kepuasan kerja.

Studi terdahulu mengatakan bahwa ketrampilan politik diperlukan untuk keterlibatan pribadi yang efektif dalam organisasi (Mintzberg, 1983) hal ini ditandai dengan persepsi sosial dan kemampuan menyesuaikan perilaku seseorang untuk berbeda dan merubah kebutuhan situasional (Ferris et al., 1999, 2005). Brouer et al. (2011) mengasumsikan bahwa ketika persepsi politik organisasi tinggi, individu mungkin tidak yakin bahwa kerja keras akan menghasilkan hasil yang diinginkan. Brouer et al. (2011) menunjukkan ketrampilan politik itu tidak memoderasi hubungan antara persepsi politik organisasi dan hasil yang terkait dengan pekerjaan (kepuasan kerja, kinerja, dan 
Jurnal Bisnis dan Kewirausahaan

komitmen yang dinilai manajer). Ketrampilan politik dianggap sebagai pola kompetensi sosial yang komprehensif, yang mencerminkan manifestasi kognitif, afektif dan perilaku, dan memperagakan efek pada diri sendiri dan orang lain (Ferris et al., 2007). Gallagher dan Laird (2008) menyatakan bahwa ketrampilan politik melemahkan pengaruh hubungan antara persepsi politik organisasional dan kepuasan kerja.

\section{F. KESIMPULAN}

Penelitian ini bertujuan menguji pengaruh hubungan persepsi politik organisasional pada kepuasan kerja yang di moderasi oleh ketrampilan politik. Berdasarkan hasil pengelolaan data menjelaskan bahwa tidak semua hipotesis dalam studi ini terdukung. Berdasarkan hasil analisis yang telah dilakukan maka dapat ditarik kesimpulan sebagai berikut: (1) Persepsi Politik Organisasional berpengaruh negatif pada Kepuasan Kerja (2) Ketrampilan Politik tidak memoderasi hubungan negatif antara Persepsi Politik Organisasional dan Kepuasan Kerja.

Berdasarkan hasil analisis data dalam penelitian ini secara statistik membuktikan bahwa persepsi politik organisasional berpengaruh negatif terhadap kepuasan kerja. Hasil penelitian ini didukung oleh penelitian Ferris et al., (1989) bahwa karyawan dengan persepsi politik organisasional yang tinggi tidak puas dengan pekerjaannya dan persepsi politik organisasional yang rendah akan membawa
Vol-13/No-2/Oktober/2020

kepuasan kerja yang tinggi bagi karyawan. Hasil studi yang sama dilakukan Rawwas et al., (2018) yang menyatakan bahwa persepsi politik organisasional berhubungan negatif terhadap kepuasan kerja. Hubungan negatif ini menunjukkan bahwa dilingkungan persepsi politik organisasional, karyawan akan melihat perlakuan yang tidak sama yang akan menciptakan rasa ketidakpuasan terhadap suatu pekerjaan. Berdasarkan hasil penelitian terdahulu dan hasil penelitian yang telah dilakukan dapat dimaknai bahwa persepsi politik organisasional berhubungan negatif terhadap kepuasan kerja karyawan.

\section{IMPLIKASI MANAJERIAL}

Rumah Sakit Jiwa Daerah Surakarta dan RS PKU Muhammadiyah Surakarta dapat meningkatkan kepuasan kerja karyawannya dengan membuat teamwork yang baik antar karyawan dan selalu memberi himbauan kepada seluruh karyawan baik dalam pertemuan rutin untuk tetap melakukan tugas dan tanggungjawab sesuai dengan SOP atau ketentuan yang berlaku. Karna dengan begitu, kepuasan kerja karyawan akan terpenuhi dan kerjasama antar karyawan akan terlaksana dengan baik sehingga pekerjaan yang dilakukan tidak membuat karyawan merasa tidak puas terhadap pekerjaan yang dilakukan sesuai dengan ketrampilan kerja masing-masing karyawan. 


\section{REFERENSI}

Adams A., Lugsden E., Chase J., Arber S. \& Bond S. (2000) Skill mix changes and work intensification in nursing. Work, Employment and Society 14, in press.

Ahearn, K. K., Ferris, G. R., Hochwarter, W. A., Douglas, C., \& Ammeter, A. P. (2004). Leader political skill and team perfomance. Journal of Management, 30, 309-327.

Algifari, 2000. Analisis Statistik Untuk Bisnis Dengan Regresi, Korelasi Dan Non Parametik : Edisi Pertama. Yogyakarta : STIE YKPN.

Belfield, C. R., R. D. F. Harris. (2002). How Well Do Theories of Job Matching Explain Variations in Job Satisfaction Across Education Levels? Evidence for UK Graduates. Applied Economics, 34(5), 535-548.

Brouer, R. H., Harris, K.J. and Kacmar, K.M. (2011). The moderating effects of political skill on the perceived politics-outcome relationships. politics-outcome relationships. Journal of Organizational Behavior, 32, 869-885.

Cammann, C., Fichman, M., Jenkins, D., \& Klesh, J. (1979). The Michigan organizational assessment questionnaire. Ann Arbor, Ml: University of Michigan.
Campbell, A. C. (1976). The quality of American life: Perceptions, evaluations, and satisfactions. Russell Sage Foundation.

Chang, C.-H., Rosen, C. C., \& Levy, P. E. (2009). The relationship between perceptions of organizational politics and employee attitudes, strain, and behavior: A meta-analytic examination. Academy of Management Journal, 52(4), 779801.

Chen, Yei-Yi., \& Fang, Wenchang. (2008). The Moderating Effect of Impression Management on the Organizational Politics-Performance Relationship. Journal of Business Ethics, 79:263277.

Coomber, B., \& Barriball, K. L. (2007). Impact of job satisfaction components on intent to leave and turnover for hospital-based nurses: A review of the research literature. International Journal of Nursing Studies, 44(2), 297-314.

Dawis, R. V., \& Lofquist, L. H. (1984). A psychological theory of work adjustment: An individual-differences model and its applications. Minneapolis: University of Minnesota Press.

Drory, A. (1993). Perceived political climate and job attitudes. Organizational Studies, 14, 59-71. 
Edwards, K. (1990). The interplay of affect and cognition in attitude formation and change. Journal of Personality and Social Psychology, 59(2), 202.

Ellars, K. P. (2008). Moderating effects of political skill, perceived control, and job-related self-efficacy on the relationship between negative affectivity and physiologi cal strain. Journal of Organizational Behavior, 29, 549-571.

Ferris, G. R. Treadway, D. C., Kolodinsky, R. W., Hochwarter, W. A., Kacmar, C. J., Douglas, C., \& Frink, D. D. 2005. Development and validation of the political skill inventory. Journal of Management, 31: 126-152.

Ferris, G. R., Russ, G. S., \& Fandt, P. M. (1989). Politics in Organizations. In Impression Management in the Organization, R.A. Giacalone and P. Rosenfeld (eds). Hillsdale: NJ: Lawrence Erlbaum.

Ferris, G. R., \& Kacmar, K. M. (1992). Perceptions of organizational politics. Journal of Management, 18(1), 93-116.

Ferris, G. R., Frink, D. D., Galang, M. C., Zhou, J., Kacmar, M. K., \& Howard, J. L. (1996). Perceptions of organizational politics: Prediction, stress-related implications, and outcomes. Human Relations, 49, 233-266.
Ferris, G. R. (1999). Development and initial validation of the political skill inventory, Paper presented at the Annual Meetings of the Academy of Management. Chicago.

Ferris, G. R., Treadway, D. C., Kolodinsky, R. W., Hochwarter, W. A., Kacmar, C. J., Douglas, C., et al. (2005). Development and validation of the political skill inventory. Journal of Management, 31, 126-152.

Ferris, G.R. et al. (2005b). Development and validation of the political skill inventory. Journal of Management, 31, pp. 126-152.

Ferris, G. R., Darren C. Treadway., Pamela L. Perrewé., Robyn L. Brouer., Ceasar Douglas., and Sean Lux. (2007). Political skill in organizations. Journal of Management, 32, 290320.

Ferris, G. R.-C.-C. (1998). Organizational Politics: The nature of the relationship between politics perceptions and political behavior. In S. B. Bacharach \& E. J. Lawler (Eds.). Research in the sociology of organizations.

Fung-Kam, L., 1998. Job satisfaction and autonomy of Hong Kong registered nurses. Journal of Advanced Nursing 27 (2), 355-363.

Gallagher, V. A. (2008). The combined effect of political skill and political decision making on job satisfaction. Journal of 


\section{Vol-13/No-2/Oktober/2020}

Applied Social Psychology, 38, 2336-2360.

Gallagher, V.C. and Laird, M.D. (2008). The combined effect of political skill and political decision making on job satisfaction. Journal of Applied Social Psychology, 38, pp. 23362360.

Ghozali, Imam. (2005). Aplikasi Analisis Multivariate Dengan SPSS. Semarang : Badan Penerbit UNDIP.

Gohel, K. (2012). Psychological capital as a determinant of employee satisfaction. International Referred Research Journal, 3(36), 34-37.

Golbasi, Z., Kelleci, M. and Dogan, S. (2008). Relationships Between Coping Strategies, Individual Characteristics and Job Satisfaction in a Sample of Hospital Nurses: Cross-Sectional Questionnaire Survey.

Herzberg, B. (1959). The motivation to work. New York: John Wiley.

Hochwarter, W., Kacmar, C., Perrewe', P., \& Johnson, D. (2003). Perceived organizational support as a mediator of the relationship between politics perceptions and work outcomes. Journal of Vocational Behavior, 63, 438-456.

Jan, D. V. (2011). The psychologization of humanitarian aid: skimming the battlefield and The psychologization of humanitarian aid: skimming the battlefield and. Hist Hum Sci, 24(3), 103-122.

Kacmar, K.M., Andrews, M.C., Harris, K.J. and Tepper, B.J. (2013). Ethical leadership and subordinate outcomes: the mediating role of organizational politics and the moderating role of political skill. Journal of Business Ethics, 115, pp. 33-44.

Kacmar, K. M., \& Baron, R. R. (1999). An examination of the perceptions of organizational politics model: replication and extension. Human Relations, 52(3), 383-416.

Kacmar, K. M. (1999). Organizational politics: The state of the field, links to related processes, and an agenda for future research. Research in Personnel and Human Resources Management, 17, 1-39.

Larson, E., Lee, P.C., Brown, M.A., et al., 1984. Job satisfaction: assumptions and complexities. Journal of Nursing Administration 14 (1), 31-38.

Locke, E. A. (1969). What is job satisfaction? Organizational Behavior and Human Performance, 4(4), 309-336.

Locke, E. A. (1976). The nature and causes of job satisfaction. In M. D. Dunnette (Ed.). Handbook of industrial and organizational psychology. Chicago: Rand McNally.

Mayes, B. T., \& Allen, R. W. (1977). Toward a definition of organizational politics. 
Academy of Management Review, 2(4), 672-678.

Md. Rifayat Islam, M. T. (2012). Analysis of the Factors that Affect Job Satisfaction: A Case. European Journal of Business and Management, 4(4), 35-46.

Medison, L. M., Allen, R. W., Porter, L. W., Renwick, P. A., \& Mayes, B. T. (1980). Organizational politics: An exploration of managers' perceptions. Human Relations, 33, 79-100.

Meisler, G., \& Vigoda-Gadot, E. (2014). Perceived organizational politics, emotional intelligence and work outcomes: empirical exploration of direct and indirect effects. Personnel Review, 43(1), 116-135.

Miller, B. K., Rutherford, M. A., \& Kolodinsky (2008). Perceptions of Organizational Politics: A Metaanalysis of Outcomes. Journal of Business and Psychology, 22(3), 209-222.

Mintzberg, H. (1983). Power in and around Organizations. Englewood Cliffs: Prentice-Hall.

Moorman, R. H. (1993). The influence of cognitive and affective based job satisfaction measures on the relationship between satisfaction and organizational citizenship behavior. Human Relations, 46(6), 759-776.
Olson, J. M., \& Zanna, M. P. (1993). Attitudes and attitude change. Annual Review of Psychology, 44, 117-154.

Parker, C. P., Dipboye, R. L., \& Jackson, S. L. (1995). Perceptions of organizational politics: An investigation of antecedents and consequences. Journal of Management, 21, 891-912.

Perrewe', P. L., Zellars, K. L., Ferris, G. R., Rossi, A. M., Kacmar, C. J., \& Ralston, D. A. (2004). Neutralizing job stressors: Political skill as an antidote to the dysfunctional consequences of role conflict stressors. Academy of Management Journal, 47, 141-152.

Rawwas, M. Y. (1997). The Management of Conflict by Utilizing Individual Power Sources: A Retailers' Perspective. Journal of Business Research, 40(1), 49-64.

Rawwas, M. Y. (2003). The Influence of Leadership Styles, Conflict Management, and Individual Characteristics on Motivation: A Cross-Cultural Study of Business Supervisors. Journal of Asian Business, 19(1), 37-65.

Robbins SP, J. T. (2007). Organizational behavior. Prentice Hall.

Robyn L. Brouer, K. J. (2011). The moderating effects of political skill on the perceived politics-outcome 
relationships. Journal of Organizational Behavior, J. Organiz. Behav, 32, 869-885.

Rosen, C.C. and Levy, P.E. (2013). Stresses, swaps, and skill: an investigation of the psychological dynamics that relate work politics to employee performance. Human Performance, 26, pp. 44-65.

Sang-Bing Tsai (2018). Using the DEMATEL model to explore the job satisfaction of research and development professionals in china's photovoltaic cell industry. Journal of Renewable and Sustainable Energy Reviews, 81, 62-88.

Sonal Saxena,Kalpana Tomar, Shivangi Tomar (2005). Impact of Job Satisfaction on Organizational Citizenship Behavior. SSRN electronic journal volume issue 2019.

Sıgrı, U., \& Başar, U. (2015, May). Etik liderliğin iyileştirici etkisi üzerine görgül bir araştirma (An empirical research on healing effect of ethical leadership). Paper presented at the 23'üncü Ulusal Yönetim ve Organizasyon Kongresi (23rd National Management and Organization Congress Proceedings), Muğla, Türkiye.

Spector, P.E., 1997. Job Satisfaction: Application, Assessment, Causes, and Consequences. Sage, Thousand Oaks, CA.
Sugiyono, 2018. Metode Penelitian Manajemen Bandung : Penerbit Alfabeta.

Tovey, E.J., Adams, A.E., 1999. The changing nature of nurses' job satisfaction: an exploration of sources of satisfaction in the 1990s. Journal of Advanced Nursing 30 (1), 150-158.

Ulla Hytti, T. K. (2013). Determinants of job satisfaction for salaried and selfemployed professionals in Finland. $J$ Human Resour Manag, 24(10), 2034-2053.

Vigado-gadot, E. (2007). Leadership style, organizational politics, and employees' performance an empirical examination of two competing models. Personnel Review, 36(5), 661-683.

Vigoda-Gadot, E. \& I. Talmud. (2010). Organizational politics and job outcomes: The moderating effect of trust and social support. Journal of Applied Social Psychology, 40(11), 2829-2861.

Vieira, Jose A. Cabral. 2005. Skill Mismatches and Job Satisfaction. Economics Letters, 89 (1): 39-47.

Vroom, V. H. (1964). Work and motivation. New York: Wiley.

Wang W, H. P. (2012). Understanding user satisfaction with instant messaging: 
an empirical survey study. J Human-

Comput Interact, 28(3), 153-162.

Zellars, K.L., Perrewé, P.L., Rossi, A.M.,

Tepper, B.J. and Ferris, G.R. (2008).

Moderating effects of political skill, perceived control, and job-related self-efficacy on the relationship between negative affectivity and physiological strain. Journal of Organizational Behavior, 29, pp. 549-571. 